Página inicial: 87 - Página final: 96

TIPO DE ARTÍCULO: de Investigación

\title{
CAPITAL, SUJETO Y CIUDAD. LECTURAS DE LA CIUDAD Y LA CRISIS HUMANISTA. EL CASO MEDELLÍN.
}

\author{
CAPITAL, SUBJECT, AND CITY. READINGS OF THE CITY AND THE HUMANISTIC \\ CRISIS: THE MEDELLIN CASE.
}

\author{
Recibido: Agosto 2013 Revisado: Noviembre 2013 Aceptado: Marzo 30 de 2014
}

\author{
Por: Edison Villa Holguin ${ }^{1}$, Alfonso Insuasty Rodriguez ${ }^{2}$.
}

\section{RESUMEN.}

El presente texto presenta un resultado del análisis de la información resultante del I Foro Contra-Hegemónico Urbano, realizado en la ciudad de Medellín, culmen de una serie de conversatorios de ciudad realizados durante el año 2013, se trata de un insumo que se pensó en cuatro apartes donde el centro es la relación entre ciudad, capitalismo, guerra y sujetos en la ciudad de Medellín, así mismo, se enfatiza en la presencia de la guerra de manera más explícita y se expone cómo el capitalismo que ingresa de manera contundente, sufre trasformaciones ligadas al modelo de las city marketing, la ciudad de los servicios y la fuerte presencia de un discurso globalizador, que también tiene efectos en la retícula urbana y las clases sociales, sujetos y/o sectores populares. Finaliza el texto intentando una caracterización de los sujetos que las dinámicas anteriores producen como alienados, explotados u oprimidos, pero también como resistencia y/o emancipación para cerrar con planteamientos - retos, de la investigación social.

\section{PALABRAS CLAVE.}

ciudad mercado, consumo, alienación, sujeto, desarrollo.

\begin{abstract}
.
This current text presents a result of analysis of the resulting information of the First Urban Counter-Hegemonic Forum, held in the city of Medellin, as a culmination of a series of city discussions carried out during the year 2013. It deals with an input that was thought in four sections, where downtown is the relationship among city, capitalism, war, and subjects in the city of Medellin. Likewise, it emphasizes the presence of the war more explicitly and it exposes how the capitalism that enters in a forceful way, undergoes transformations linked to the model of the city marketing, the city of the services, and the strong presence of a globalizing discourse, that also has effects on the urban screen and the social classes, subjects, and / or popular sectors. The text ends up trying to characterize the subjects, that in the previous dynamics, produce as being alienated, exploited, or oppressed, but also as resistance and/or emancipation in order to close with approaches - challenges, corresponding to the social research.
\end{abstract}

\section{KEY WORDS.}

City Market; Consumption; Alienation; Subject; and Development.

\footnotetext{
${ }^{1}$ Magister en Educación, formador popular, Docente Universitarios, integrante del grupo de investigación para la transformación Kavilando. interandinos@yahoo.es.

${ }^{2}$ Docente Universitario, integrante del grupo de investigación para la transformación Kavilando. Alfonso.insuasty@gmail.com.
} 


\section{Introducción.}

Medellín, la ciudad del reality y de la pasarela, ha querido y quiere ingresar a las grandes ligas de las ciudades estado y por supuesto el precio será alto, pues se quiere reafirmar y legalizar un modelo hegemónico de ciudad, que juegue en el libre comercio, indiferente a la concertación con la población, definiendo por decreto, la planeación del territorio, el desarrollo social y la proyección futura de la población en general, dándole paso a la exclusividad de los negocios del comercio internacional y al consumo de enlatados que traen las cadenas de mercaderes de la globalidad del norte.

Se ha pretendido gobernar a Medellín como un gran centro comercial, un escenario de feria que se vende a punta de propaganda, orden privado y policial. Tal y como se deja ver en sucesivos Planes de Desarrollo de Medellín hasta el 2015. (Franco Restrepo, 2011).

En ésta lógica y como máxima expresión de este proyecto de ciudad para el mercado global, en abril de 2014, la población de la ciudad de Medellín, presencio un espectáculo de orden global, un verdadero Circo como lo llamó Jordi Borja, el WUF7: El Séptimo Foro Urbano Mundial, promovido por ONU - Hábitat, un escenario para proyectar el futuro de la urbes a nivel global. En este escenario es que aparecen eslogan como: "Medellín la más innovadora", "Un hogar para la equidad y la vida": titulares de ciudad, elaborados por expertos de Marketing contratados por la administración municipal para vender una imagen que en últimas, desdibuja la real realidad de la ciudad. (Valencia Gil, 2014).

Contexto. Las relaciones Capital y Ciudad.

En Colombia, entre 1920 - 1940 las ciudades fueron creciendo y transformándose de manera radical debido a la llegada de comunidades campesinas, indígenas, negras, raizales quienes por efecto del desplazamiento forzado, sea por la violencia armada o la pobreza, tenían que abandonar sus tierras y llegar a re-buscarse un lugar en la urbe, al perderse presencia en los campos, se asegura miseria en las ciudades.

La sobrepoblación urbana en Colombia fue motivada por dos condiciones, la inserción económica por la demanda de la industria local y la fuerza de la guerra que padecemos desde mediados del siglo $\mathrm{xx}$ hasta nuestros dias. La primera tiene que ver con el hito fabril que inicio en los años 50, pues el imaginario colectivo de la época, creyó que los grandes centros urbanos mejorarian las condiciones de accenso social tratando de superar el olvido y la decidia de las políticas estatales, además de la violencia estructural del sistema económico hacia el mundo rural. La segunda, se da por la coyuntura bélica derivada de los diversos conflictos políticos que datan desde la década del 40, ejerciendo una aplicación de violencia escalonada en los campos, hasta el día de hoy.

A partir de dichos fenómenos sociológicos, los campesinos fueron arrojados al mundo implacable de la urbanidad y a los perjuicios de la idea de progreso de la modernidad occidental. Tal situación invirtió las proporciones demográficas, pues del $70 / 30$ de la población en el campo en los años 50s se pasó al 70/30 en las ciudades de hoy. La demanda obrera expandió la ciudad desde los años 60s, las 
inmigraciones se adaptaron y sometieron a los hábitos citadinos, aprovechando las supuestas ventajas de accesibilidad y desarrollo, adecuando las prácticas campesinas al individualismo y la competencia del ámbito urbano.

Las ciudades fueron creciendo y organizando sus barrios como receptoras de desplazados y despojados por la violencia y como centros de concentración de los obreros. Entrada la época de la industrialización regional se tensionan aún más las relaciones entre la "ciudad naciente y excluida" con la "Ciudad Formal pensada desde las élites" la visagra será entonces la necesidad de "mano de obra" para la producción industrial. Así, se inicia un proceso de asimilación y de transformación del "ser campesino" al "ser obrero", lo cual genera la inclusión de un amplio sector de estas población, que venía del campo, a la producción industrial como mano de obra a bajo costo, haciendo que estos habitantes "aporten a la ciudad formal pensada por las élites", es decir, al crecimiento económico de la creciente urbe.

En Medellín, no toda la población migrante inmersa en la urbanidad fue despojada de sus particulares formatos culturales como campesinado, los valores comunitarios, de vecindad y el apoyo colectivo se conservaron sobre todo en las poblaciones que ocuparon las laderas de la ciudad, generándose así, en algunos casos y zonas, identidad y arraigo popular como comunidades al margen del desarrollo hegemónico.

De esta forma, algunas comunidades campesinos desarraigadas, ubicados en la periferia, empiezan a poner en marcha su barrio, a planearlo a su estilo y alcance, construyendo formas de gobierno propio, aportando sus saberes, lo que el campo les enseñó como la confianza y la solidaridad, virtudes que les permitían generar los comités de trabajo que posibilitaron construir la mayor parte de los actuales sectores populares, donde lo vecinal, lo local y la colectividad no dejan de existir. Se desarrolla asi, un habitad hibrido de semi-ruralidad y nuevos nichos de relación social y cultural a partir del intercambio de costumbres y relaciones de auténtica acogida y ayuda mutua.

Esta capacidad organizativa les permitió, a pesar de la exclusión, luchar de manera constante, por la exigibilidad de sus derechos, la inclusión, resistencia y capacidad para planear su territorio, logrando así ir teniendo acceso a los servicios básicos, alcantarillado, agua, educación, salud, etc; ese acumulado y esa memoria de acción colectiva, pervive en algunos pobladores, quienes reivindican el reconocimiento de su papel político, como sujetos constructores de sociedad y como voz necesaria y decisiva en las intervenciones administrativas sobre el habitad de la ciudad.

Ignorando el ancestral principio de que "los problemas locales, requieren soluciones locales". La administración tradicionalmente no ha considerado de manera real estas expresiones organizativas populares locales, por el contrario se empeña en implementar las políticas globales acelerando las reformas económicas y jurídicas sobre el territorio, acrecentando la violencia estructural.

En el ambiente rueda la idea de que la pobreza y la miseria es un problema de los pobres, que no es un problema de toda la sociedad.

El estado, la institucionalidad, de manera estructural, ha ido obligado a la población no solo a vivir sin garantías sociales y sin protección de su vida en dignidad, sino a 
vivir a pesar de sus instituciones. El modelo de ciudad neoliberal, se ha encargado de agudizar la crisis humanitaria que padece el contexto citadino, fenómeno conocido como la deshumanización Urbana; en Colombia en general y en Medellín en particular, se ha permitido y promovido la extrema pobreza, es así como las dirigencias y sus leyes, persisten en que la sociedad entera camine hacia el sálvese quien y como pueda, reproduciendo en lo cotidiano, las problemáticas sociales, la violencia, la corrupción y la guerra; que para el caso Medellín desde los años 70s se presenta en variables de sociedad degradada como narco-paramilitarismo, narcopolitica y para-politica (Balbin \& Insuasty Rodriguez, 2010).

La pobreza, en crecimiento, al igual que la violencia, pasa a ser un buen negocio para la mayoría del empresariado del orgullo paisa, en tanto sus negocio a partir de la pobreza y las necesidades de los obreros y campesinos migrantes que en búsqueda de mejores condiciones económicas se adaptan a la ilegitimidad del formato del comercio flexible y desigual, avalado por la institucionalidad.

Es así que hoy, en el caso de Medellín, tenemos una de las urbes más desiguales del mundo en materia económica, espacialmente en Medellín se delimitan cuatro ciudades, la ocupada por la clase trabajadora de los sectores formales e informales, la ciudad campesina (50 mil personas) que no han llegado por olas de desplazamientos sino que han sido y siguen siendo sector campesino que ha ido siendo absorbidos y asfixiados por el Desarrollo el sector empresarial, rico, conformada por lo que queda de la alcurnia tradicional y la clase emergente fruto de la recapitalización generada en el narcotráfico, el contrabando y la burocracia contratista del ente administrativo y un cuarto sector, que habita la calle o bajo las calles, un sector que no cuenta.

La ciudad se transforma según las dinámicas del mercado global y no las necesidades propias.

Hoy un amplio sector de los pobladores de las laderas del área metropolitana estan regidos por las leyes de la extrema necesidad, la exclusión social, el resentimiento, la discriminación, pero también por la compulsión consumista, el sueño del éxito show, acaparar riqueza, el aislamiento individualista y un sin número de obstáculos politicos y culturales para la participación y la construcción de oportunidades de vida digna, que es otra importante y transversal arista de lucha, cultural.

Son estas, agudas problemáticas generadas por los modos de producción y distribución, que condicionan subjetividades instrumentales, mercenarias y mendicantes que el sentido común naturaliza, la sociedad y el estado justifica, afirma y legaliza. Forzando un modelo de sociedad egoísta, mezquina, estigmatizante y excluyente que se devora a sí misma.

¿Quién y desde donde se estructuran y se toman las decisiones que transforman las ciudades y los sujetos de la actualidad?. 


\section{Metodologia.}

La red llamada Foro Social Popular, de Medellín, decidió realizar una serie de conversatorios sobre las principales problemáticas de la ciudad, convocando expertos y población en general, para discutir sobre sus sentidas necesidades, servicios públicos, valores, formación, vivienda, modelos de ciudad, oportunidades laborales, entre otros temas-problemas que se trabajaron, como resultado de este ejercicio, se acordó realizar una gran jornada de Reflexión de cara incluso, al $7 \mathrm{mo}$ Foro Urbano Mundial que Naciones Unidas realizó en la ciudad de Medellín en el mes de Marzo de 2014.

Es así que el abril de 2014 se realizó en articulación con varias organizaciones sociales y grupos de investigación, se realizó el Foro Contra-Hegemónico Urbano, pensar la ciudad en la ruta y lógica que fue resultando de las reflexiones que se hicieran una año atrás en los consecutivos conversatorios y debate de ciudad en medellin, posibilitadas por el Foro Social Popular.

Se realizaron talleres, durante tres dias, se sistematizó la información general cuyas memorias se publican en la Revista Kavilando www.revistakavilando.weebly.com y de dicha sistematización y posterior discusión resulto este artículo que procura hacer una análisis de Ciudad, sus modelos, sus enfoques y la repercusión en la construcción de sujetos y capacidad organizativa para la transformación social desde abajo.

El presente texto se pensó en cuatro partes: El primer apartado, hace énfasis en la relación ciudad, capitalismo, guerra y sujetos, centrando su mirada en la situación de la ciudad de Medellín. En el segundo apartado, enfatiza en la presencia de la guerra de manera más explícita y allí se expone cómo el capitalismo que ingresa de manera contundente, sufre trasformaciones ligadas al modelo de las city marketing, la ciudad de los servicios y la fuerte presencia de un discurso globalizador, que también tiene efectos en la retícula urbana y las clases sociales, sujetos y/o sectores populares. El tercer aparado se detiene es "caracterizar" los sujetos que las dinámicas anteriores producen como alienados, explotados u oprimidos, pero también como resistencia y/o emancipación. Y el último apartado plantea retos de la investigación social.

\section{Resultados - discusiones.}

La discusión sobre la pérdida de autonomía en los sujetos y la soberanía de las naciones, tiene que ver con la visión imperial disfrazada de intercambio global. Las decisiones sobre la ciudad de Medellin, son cada vez menos pensadas para las necesidades e intereses de sus pobladores, pasan más por el criterio de la ley de mercado, que fluye formal desde las instituciones pero también informalmente como el contrabando, el narcotráfico y la guerra en tanto vehiculizan el capital de los grandes negocios internacionales.

Es así como la reacomodación del capitalismo extractivista, genera la adecuación de las ciudades como territorio receptor de desplazados, consecuencia de la aplicación de una violencia generalizada, en clave de un reordenamiento, legal e ilegal, del territorio rural en el proceso de explotación de sus recursos para la naciente producción tecnológica (energía, agua, minerales), proyecto que termina 
entrelazando y amarrando el futuro de las subregiones para satisfacer las necesidades de su centro "La Capital" de la región en tensión con los requerimientos de la Capital del País y esta a su vez, en escala hacia las lógicas del mercado internacional y los centros de poder global. Además de generar el guión por el cual se dinamizan las relaciones sociales y humanas, desde la promoción del pensamiento único mercaderista que unifica al mundo bajo una sola potestad, emular el modelo occidental utilitarista de aprovechar los recursos mientras duren y después mirar a quien se invade y a quien se le despoja. Politica de conquista y despojo empleada en nuestros territorios desde el renacimiento occidental (Vega Cantor, 2013).

La ciudad de Medellín, no escapa a ésta lógica; siendo la capital de un departamento pensado como "estratégico" para el mercado global; de manera reciente desde los años 80s con el plan empresarial "Antioquia la mejor esquina de América", venían dándose las avanzadas geo-estratégicas y militares por los recursos minerales, hídricos, entre otros. La mentalidad extractiva del administrador local, termina vendiendo con miles de artimañas legales e ilegales, los bienes colectivos de la región como el agua, extraída de los territorios cercanos de la ciudad expropiados a sangre, fuego y con la fuerza de la ley, actuando como ciudad estado, o ciudad región. Adaptación y sometimiento jurídico y económico para darle la talla al sostenimiento del estilo de vida del norte global. (Insuasty Rodriguez, Grisales Grajales, \& Gutierrez Leon, 2013).

Por otro lado, ante las necesidades de recursos de esta etapa marcada por la crisis del capital, se fue configurando la creciente ciudad como el lugar desde donde se planearía el futuro de la regiones rurales cercanas, en tanto es alli, donde se firmarian los grandes negocios que se sustentan en la extracción de las materias primas para la producción, minerales, energía, agua, agricultura industrial, etc., además el lugar desde donde se comercializarian dichos productos para el mercado nacional e internacional; se trata de una relación de dependencia funcional y parasitaria al proyecto empresarial Local en "tensión" con el proyecto de la élite Nacional; dos proyectos que aún en su tensión, se acomodan a las lógicas y tendencias del mercado global, procurando, gracias a la captura del Estado por parte de éstas élites empresariales, una posición privilegiada en la firma de grandes negocios (Franco Restrepo , 2011).

\section{El cambio de modelo y la ciudad de los servicios.}

La condición de la globalización y de apertura económica implicó un cambio en el modelo de desarrollo local y por ende los cambios de los usos del suelo para el neo-extractivismo, la captura de las fuetes de agua y la agroindustria a gran escala. Desde alli, la concentración de población urbana se empieza a entender no como fenómeno emergente sino como parte de lo planeado y la guerra es usada como factor de repoblamiento. En los años 90s las contiendas bélicas, se hacen fusionar (conflicto social y político y guerra internacional contra el narcotráfico) por dictamen y exigencia chantajista del mercado internacional. La clase dirigente aprovecha las circunstancias de la contienda con los carteles de la droga y el conflicto interno para adaptarse a la economía de guerra, ganando en beneficios particulares, además de cumplirle a la ley del norte. 
La doble moral burguesa conservadora que desde siempre acompaña el imaginario colectivo de la política Colombiana, ve el narcotráfico como el escenario perfecto para la adaptación a la economía global, convirtiendo el orden autoritario en factor de desarrollo y otros perfiles de liderazgo empresarial que asumen las dirigencias. Nuevas elites de Militares, Paramilitares y Mafias asociadas al narcotráfico administran las politicas y la justicia, surgen como redentores y orientan la economía de guerra para sí, a partir de los imaginarios y las sensaciones de seguridad y de terror, el ambiente del enemigo interno de la doctrina de seguridad nacional norteamericana y el estado de manipulación de la opinión de corte mediático.

El alcalde ya solo le queda obedecer a los financistas y empresarios.

En la lógica de enclave económico, la seudo-cultura paisa y la nueva clase política que administra las formas institucionales, utiliza el pequeño margen de manejo que les deja el capitalismo internacional, los servicios comerciales y el orden público. De allí saca provecho para su gestión, la retribuye a sus contratistas patrocinadores y a los intereses particulares y aumenta su clientela electoral. Para la custodia de la ciudad de la compra venta, se consolida el orden represivo y el enfoque policial y punitivo de la cultura metro, que hace necesario un ejército de vigilantes privados.

Los pactos de seguridad terminan generando la gran alianza con los combos delincuenciales, promoviendo escuelas de mercenarios y redes de informales con funciones policiales, la clamorosa estupidez y deseos de control de los dueños de la ciudad, ha hecho finalmente que tampoco ellos puedan ser los dueños de la ciudad, los combos relevan la institución en las barriadas y las calles terminan siendo o de ellos o de nadie. La administración ya no controla ni a sus policias, que terminan siendo cabecillas o intermediarios de las bandas delincuenciales.

La desconfianza de la mayoría de la población hacia las instituciones estatales, se genera sobre todo por la manera como están estructuradas en el marco de la democracia comercial, donde un gran el porcentaje de electores es comprado por los cacicazgos, las clientelas de contratistas del aparato oficial y las mafias políticas tradicionales asociadas al poder delictivo y en los últimos 30 años es la intimidación y obligación de los ejércitos paramilitares quienes terminan decidiendo sobre los gobernantes.

La minoría de inconformes que se expresan, son vistos bajo sigilo y sus voces pasan de agache, con la complacencia de quienes participan de la manipulación la opinión de las mayorias, para que no tengan impacto, ni emerjan argumentos críticos.

A la par un proceso paulatino de desmonte de la industria local implicaría una transformación sustancial de la ciudad, en tanto que ahora será pensada como la ciudad de "los servicios".

En éste orden, el mercado ha encontrado una ruta para vender ese concepto de individuo y paso seguido le pasa la oferta mercantil a consumir, para lograr dicho ideal triunfador y exitoso, para ello se requieren ciudades que ofertan consumo rápido, consumo de saber, técnica, servicios, todo se oferta, se muestra, se vende, ciudades de espejos. Dicho tránsito, da como resultado lógico, el aumenta el desempleo y es así que un grueso de la población se ve obligada a trabajar en la informalidad, el rebusque, obligándoles a salir a la calles para conseguir el sustento de sus familias. 
Se pasa así de la regulación del código laboral al código del comercio, se desmonta el mundo de los trabajadores y sus mínimas garantías sociales. La mitad de la población que se han quedado sin trabajo formal, termina asumiendo las consecuencias, subjetividades con marcos relacionales fracturados: familias, vecindario, individuos con el cien por ciento de su energía y su fuerza concentrada en la subsistencia, recluidos en sí mismos, extraídos de los otros. La dinámica del capital degrada y empobrece el humanismo, caldo de cultivo de todas las violencias, que se siguen reproduciendo (Franco Restrepo , 2011).

Estamos pasando de una ciudad para el hábitat, a una para el comercio y esto le roba dimensión, porque los derechos ahora están regulados por la capacidad de pago, se trata de implantar una lógica cotidiana como correlato: "todo se puede comprar y vender" y que todos son "Emprendedores" y todos son verracos, todos tienen capacidad para hacer dinero, sea como sea: todo se podrá hacer siempre y cuando logre mover capital.

En esta lógica se con-esta y convive con la ilegalidad; hoy Medellín por ejemplo, está exportando personas para el servicio sexual, para el trabajo a bajo costo (migrantes), personas para el mercenarismo internacional, la distribución de droga, para el divertimento de los visitantes de ciudades opulentas del mundo occidental, ejércitos ilegales (combos) articulados a una gran estructura para la circulación de grandes cantidades de capital.

\section{Sujetos - ciudad.}

La estrategia de "control poblacional para el reordenamiento territorial del mercado capitalista" en la captura de los recursos para el desarrollo de la economía neoliberal, ha generado violencia legal e ilegal en los territorios "estratégicos" para el desarrollo del proyecto de mercado ("desarrollo" - "progreso"), estos modelos terminan imponiéndose a la fuerza generando una "Sociedad Victimizada" que recibe toda la contundencia de la "pedagogía del terror" (Personería de Medellín, 2013).

"Calladito es mejor", es claro que la pedagogía del terror, para la domesticación, también se aplica mediante la férrea tenaza de la exclusión económica, constituyendo poblaciones enteras en zoos, bajando sus necesidades a lo más básico: el "subsistir"; es así que, seré "ser humano" en tanto pueda entrar en la lógica del mercado, o tenga recursos con qué comprar el acceso a los servicios y los derechos o tenga acceso a algún subsidio.

Se trata de una pedagogía social del miedo y el terror, que busca "romper la subjetividad" implica entonces, eliminar la capacidad organizativa de las personas, eliminar su historia, sus saberes, su capacidad de "ocuparse" de lo público para darle paso así, sin resistencia real alguna, al poder hegemónico establecido; se construye a la fuerza y gracias a la pedagogía del terror y la violencia, sujetos individualizados, sin tejido social, sin arraigo al territorio, sin una identidad cultural propia, sin referencia de un proyecto propio sino con la necesidad de incluirse en las lógicas del mercado: ser emprendedores, empresarios, ricos, consumidores.. ser humano como objeto de rentabilidad.

Por su parte, se generan dispositivos del estado y la ciencia que asumen la tarea de redireccionar "el dolor" - (victimas) que genera este sistema, buscando individualizar, 
minimizar, adaptar, patologizar. En éste orden, el mercado ha encontrado una ruta para hacer del dolor y la pobreza su nuevo-viejo, gran negocio y la puerta de entrada de una cultura del consumo adaptada a las necesidades del capital. (Romero \& Ramiro, 2012)

\section{Conclusiones.}

Recupera el Sujeto, algunos apuntes:

Investigación y formación para la transformación. Hoy requerimos fortalecer herramientas para hacer lectura de realidad, ubicarnos, establecer categoria propias para entender nuestras posibilidades reales y concretas condiciones, para trazar ruta de acción y construir proyecto o proyectos colectivos propios sobre la base de la recuperación eco-ético-política-espiritual del sujeto.

Fortalecer centros de formación propios, no es inadecuado ni lejano pensar en una Universidad desde Abajo, que realmente acoja y tramite las necesidades de los sectores campesinos, étnicos y populares

Pensarnos lo organizativo. Los sujetos que conforman y le apuestan a consolidar espacios organizativos, han de encausar sus fuerzas primero en construir sus propios objetivos de lucha a largo, mediano y corto plazo, objetivos ubicados espacial y temporalmente, con la claridad histórica suficiente que da una lectura adecuada, critica y profunda de su contexto especifico y concreto.

La planeación colectiva - estratégica - diversa, permite saber con qué recursos se cuenta, con quienes, qué acciones se han de realizar y se deben realizar, para qué, dónde y cómo realizarlas, definir en qué escenario se ha de encausar toda la fuerza para impulsar el logro del objetivo trazado.

Gestar escenarios donde se activen valores humanos para el intercambio, el buen y bien vivir, la conciencia del consumo, la agricultura urbana, la permacultura, economias alternativas, articular estas nuevas expresiones campo-ciudad, será el reto para ir construyendo otra ciudad posible. 


\section{Referencias Bibliográficas.}

Balbin , J., \& Insuasty Rodriguez, A. (2010). Las Victimas en Contextos de Violencia e Impunidad: Caso Medellin. Medellin: Instituto Popular de Capacticación.

Franco Restrepo , V. L. (2011). Medellin, orden, desigualdad, fragilidad. Medellin: Corporacion Jurídica Libertad.

Insuasty Rodriguez, A., Grisales Grajales, D., \& Gutierrez Leon, E. M. (30 de Diciembre de 2013). Conflictos asociados a la gran mineria en Antioquia. El Agora USB, 13(2), 371-397.

Personería de Medellin. (30 de diciembre de 2013). Informe Derechos Humanos 2013. Obtenido de Personeriamedellin.gov.co: http://www.personeriamedellin. gov.co/documentos/INFORME_D1.pdf.

Restrepo Marin, Janeth. (2011). Expresiones Juveniles en espacios de Violencia. El Agora USB, 11(2), 321-334.

Romero, M., \& Ramiro, P. (2012). Pobreza 2.0. Madrid: Icaria.

Valencia Gil, J. (2013 de Septiembre de 2014). "El Foro Urbano Mundial es un circo": Jordi Borja. Obtenido de El Colombiano: http://www. elcolombiano.com/BancoConocimiento/E/el_foro_urbano_mundial_ es_un_circo\%E2\%80\%9D_jordi_borja/el_foro_urbano_mundial_es_un_ circo\%E2\%80\%9D_jordi_borja.asp.

Vallejo Duque, Yani., \& Insuaty Rodriguez, Alfonso. Medellín, somos victimas del desarrollo forzado. Kavilando, 4 (1), 45-49.

Vega Cantor, R. (2013). Colombia y geopolicia hoy. El Agora USB, 367-402.

Velasquez, C. (2009). Situación actual en la Presentación de los Servicios Públicos. El Agora USB, 9 (2), 391 - 425.

Velasquez, C. (2010). Medellín desconectada... de la dignidad. Kavilando, 2 (1), $103-109$.

Velasquez, C. (2012). La politica de mejoramiento integral de barrios en Medellín. ¿ Reconquista del territorio por parte del estado?. Kavilando, 3 (2) 72 - 78.

Zemelman , H. (1998). Sujeto: existencia y potencia. Mexico: Anthropos. 